\title{
East Asian Collections and Organizational Transformation in Academic Libraries
}

\author{
Hitoshi Kamada
}

\begin{abstract}
Special aspects of East Asian collections, induced by constraints in handling vernacular-language information from East Asia, have distanced those collections from mainstream academic library administration. Meanwhile, substantial organizational transformation is changing the landscape of academic library management. Quality management, staffing changes, a desire for demonstrated efficiency and effectiveness, and strategic planning are some of the major forces of organizational change in academic libraries now having an effect on East Asian collections. This article explores how organizational changes affect East Asian collections, entities often marginalized in this era of transformation, and how East Asian collections should respond to the changes.
\end{abstract}

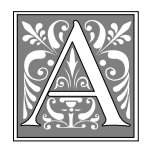

fter World War II, East Asian studies programs sprang up on campuses across North America in response to a growing cultural, political, and economic interest in East Asia. As a result, many college and university libraries created East Asian collections to support the research and curricular needs of East Asian studies programs with information resources on China, Japan, and Korea. An East Asian collection's functions emanate from its role of providing information from overseas in vernacular languages, and from the limitations and difficulties in handling vernacular languages produce the uniqueness of such a collection in the North American library system. East Asian languages, being nonroman, are forced to fit into a roman-language environment where information resources are treated and arranged by the practices developed for roman languages. Running an East Asian collection requires subject librarians and staff with language expertise and special work processes tailored to acquire, process, and disseminate information in East Asian vernacular languages. The collection serves a clearly defined group of users, mostly faculty and graduate students capable of using East Asian languages. It is often placed as a branch library or in a separate area in the library and run by dedicated staff with language expertise. The East Asian collection tends to be self-sufficient in technical processing, reference services, and, in some places, circulation services. ${ }^{1}$

Thus, East Asian collections have been more or less isolated from the mainstream academic library setting. However, they were not uncomfortable being that way 
when academic libraries were in a relatively benign environment and were well funded. In the past, mainstream library management might look at an East Asian collection as something foreign but was content with letting it be. However, in the 1990s, the academic library environment changed drastically. Decreasing financial support, rising costs of acquiring information, increased competition from other information service providers, rapid technological changes, and changing and expanding information needs of academia have made those "good old days" a thing of the past.

\section{East Asian librarians often need to spend extra time establishing close communication channels with foreign book vendors and working with a cumbersome book distribu- tion system in certain regions.}

This turbulent environment made academic libraries look for new ways to cope. They often found that tackling emerging issues in old ways within existing organizational structures did not work well. This forced libraries to change their organization in terms of beliefs, values, and structure. ${ }^{2}$ Academic libraries implemented various organizational changes with the introduction of a wide array of management techniques used in other industries, and there is abundant literature that deals with this organizational transformation in the academic library setting. In the area of East Asian librarianship, Ai-Hwa $\mathrm{Wu}$ discussed its changing role and environment and touched on the trend that East Asian studies librarians are becoming more involved in mainstream librarianship and its transformation. ${ }^{3}$ Are East Asian collections able to maintain their "happily isolated" places in academic libraries amidst the onslaught of organizational change? How should East Asian studies librarians react to these changes, and what issues will emerge? Because organizational changes are becoming frequent in every sphere of the academic library environment, it is time to shed light on the unique place of East Asian collections in the academic library within the context of organizational change.

\section{Special Aspects of East Asian Collections}

Serving a well-defined group of users with vernacular-language information resources, East Asian collections have several unique aspects. Many of the services and processes in East Asian collections require language expertise of librarians and support staff. The practices of publishing markets and scholarly communications in East Asia call for specialized knowledge and different approaches to acquiring, processing, and disseminating information. These practices sometimes make simple tasks such as ordering books more cumbersome than performing similar library tasks such as ordering English-language titles from established book vendors in North America. For example, even information on publications in East Asia may be difficult to obtain. ${ }^{4}$ East Asian librarians often need to spend extra time establishing close communication channels with foreign book vendors and working with a cumbersome book distribution system in certain regions. Even arranging payment with a foreign vendor can pose challenges because of differences in business practices and currency exchange. Although their magnitude has become smaller as globalization of trade progresses in the region, these issues still exist.

Technical processing, especially cataloging, of East Asian-language materials requires staff with language expertise and special work procedures. The creation of vernacular data fields in cataloging records requires extra time and special software for creating vernacular characters. Transliteration of East Asian-language text for cataloging is often a difficult and time-consuming process. A nonphonetic script, intonation, multisyllabic words, and different romanization systems all contribute to the difficulty in creating cataloging records for East Asian materials in the romanized format. ${ }^{5}$ Providing reference services re- 
quires knowledge of reference materials in vernacular languages and different search procedures for locating vernacular-language information in print and electronic formats. Furthermore, providing electronic information from East Asia poses challenges of overcoming language differences in computer processing and reconciling disparities in copyright regulations and/or vendor licensing restrictions.

Diane E. Perusheck summarized the administrative challenges facing East Asian collection branches in a research library setting. First, an East Asian collection, requiring dedicated staff with language skills and serving a small user population, is inherently not cost-efficient. It also bears additional costs of creating and maintaining vernacular records in the cataloging system. Moreover, ordering East Asian-language material is a more time-consuming process. High material and shipping costs, with associated overhead costs, require special budgetary considerations. ${ }^{6}$ Because of the self-sufficient operation necessary to accommodate the tasks required to handle nonroman languages, the East Asian collection often does not fit in the mainstream reporting structure of the library system and is often marginalized in the library's policy-setting and planning. Located in a marginalized area, an East Asian studies librarian can be in the middle of conflicts between the library's directives and the specific interests of the academic department they serve because they need to champion the closely defined group of users in the department. ${ }^{7}$

East Asian collections share some of these issues with other area studies collections, such as Latin American and Slavic collections. Often placed in branches, East Asian collections share the administrative difficulties that any branch library faces because of its physical distance from the main library. Moreover, East Asian materials need a lot of special handling because of the special characteristics of East Asian languages and the need to integrate them into a roman-language environment in the library system.
This language limitation affects various tasks performed in an East Asian collection. These issues have been around for years, and for library administration, it made sense to let East Asian collection staff run the collection independently because it had so many special aspects. As a result, East Asian studies librarians certainly felt marginalized from the mainstream library but probably did not care too much about it as long as they had sufficient autonomy to run the collection and steady funding support. Thus, tacit noninterference agreements were formed.

\section{Concepts Driving Change}

The era of traditional staffing arrangements and steady financial support is gone now. Organizational changes are omnipresent in the contemporary academic library environment; some are

\section{East Asian collections should be ready to respond to any changes in customer needs and need to do more to better understand and anticipate customer needs}

drastic, but others are small and gradual. People in the library profession have heard a lot of management buzzwords such as total quality management (TQM), systems thinking, and learning organization, to name a few. Many academic libraries have implemented numerous management approaches and principles in their workplace; some have been successful, and others less so. In either case, these new management approaches and principles have brought about a major transformation in the ways academic libraries are structured and provide services to customers.

\section{From Collection Focus to Customer Focus}

An array of TQM concepts has permeated the thinking of many library administrators whether they fully embrace them or not. TQM already sounds like an obsolete phrase in the fast-changing world of management, but its fundamental con- 
cept of customer focus still holds true and is a driving force for organizational change everywhere. ${ }^{8}$ Customers define services, not internal processes or mandates; therefore, establishing a rapport between the library and its customers becomes a more serious business. ${ }^{9}$ In the library field, this is a shift from collectionoriented service delivery based on the storage of materials to access-oriented service delivery where customer satisfaction with information access is primary. ${ }^{10}$

East Asian librarians are no exception in recognizing this trend of moving to a customer focus. ${ }^{11}$ Serving a small number of closely defined users, East Asian studies librarians are well positioned to understand customer profiles and needs in detail. Customer demands are always changing, accelerated by changing technologies, research trends, and career prospects in modern society. Simply satisfying the existing needs of the East Asian studies department is no longer enough. East Asian collections should be ready to respond to any changes in customer needs and need to do more to better understand and anticipate customer needs.

Being closer to customers, it seems easy for an East Asian studies librarian to be customer focused if she or he chooses this approach. In fact, though customer focus sounds new to some academic librarians, it is not a new concept as long as their libraries' mission continues to "support" research and teaching on campus. However, customer focus as a management concept has more organizational implications and calls for implementation of various other management techniques. It is not just about one librarian becoming more customer conscious but, rather, about developing changes in the whole organization's mind-set. Moreover, in the academic library setting, moving to a customer focus can become complicated when an academic library puts forward this concept across the entire organization. Can the library satisfy all customer groups with diverse needs, including customers in East Asian studies, with finite financial resources?

\section{Continuous Quality Improvement}

When customer focus gains significance in the organization, it naturally drives the desire for quality. Ensuring the quality of services is fundamental to gaining customer satisfaction. The desire for quality is an honest desire on the part of service providers to provide high-quality services to their identified customers. ${ }^{12}$ As an information service professional, every librarian should have this desire for quality. However, librarians are not the only ones who provide services to customers. All the workers in the library should have this desire and work toward providing high-quality services as a whole. Self-discipline of individual librarians is not enough. It calls for an organization-wide effort to make it happen. This is where so-called quality management comes in.

Among several quality management approaches, TQM stands out as the most often used and heard approach. Although TQM can be defined in many ways, its essence has always been "continuous improvement of all processes driven by customer satisfaction." Everyone in the organization gets involved in quality improvement, and management fully supports it by building an organizational commitment to quality. ${ }^{13}$

However, several academic libraries' attempts to implement continuous process improvements have resulted in mixed success. One of the barriers identified by Susan Jurow and Susan B. Barnard is the librarian mind-set on quick fixes rather than on a systematic examination of processes and problems necessary for continuous quality improvement. ${ }^{14}$ Jurow and Barnard argue that librarians are accustomed to solving problems quickly and are impatient with the often time-consuming process of identifying the root causes of problems and initiating long-term fixes. This tendency toward quick fixes is just as likely to exist in a specialized setting such as an East Asian collection as in the typical academic library setting. Serving a small user population with limited staff does not seem to encourage this sort of thinking-system- 
atic examination of a problem for a longterm fix. Similarly, TQM sounds foreign to many business owners who run small neighborhood shops.

The professionalism of librarians, based on tradition, standards, and respected bodies of knowledge, can be in conflict with the customer-focused approach of TQM, where customer needs primarily define the services that librarians should provide, not professionalism. ${ }^{15}$ East Asian librarians, whose positions are highly specialized in the library, may well share this sense of professionalism. Knowledge of the collection and information resources in the subject and established relationships with the academic department and book vendors are embedded in the minds of individual librarians. This is in contrast with TQM practices, where all the business processes are shared more openly and are well documented and where all business problems are communicated and systematically examined for long-term fixes and process improvement. In an environment where the professionalism of individuals dominates, transfer of knowledge does not happen effectively and smoothly. For example, when an incumbent librarian leaves the library, all the knowledge of customers and services goes with that person and continuity-of-service quality is broken.

Continuous process improvement works effectively when the process of producing goods or services flows continuously with little variation. One of the most effective situations is the automobile production line, where inputs are supplied continuously for mass production of the same type of vehicle. In the library setting, process improvement seems more successful in the areas that constantly handle a large volume of tasks with little variation. For example, the University of Arizona Library has been successful in deploying process improvement approaches in areas such as book reserves, interlibrary loan (ILL) processing, and book-shelving. ${ }^{16}$ Continuous process improvement in such areas makes a library able to guarantee the delivery of the set level of quality services within a set time frame.

In an East Asian collection, however, tasks involve more irregularities, many of which are beyond the control of an individual library. For example, book acquisition processes for East Asian materials can vary significantly depending on availability of the books sought, business practices of foreign book vendors, shipping

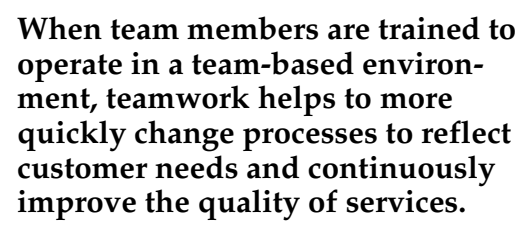

constraints, and so on. When purchasing books from a less-developed market in East Asia, irregularity of process increases even more. This makes the East Asian collection hesitant to set targeted standards for processing times of book acquisition. The processing of interlibrary loans is another area that poses great irregularity. Despite remarkable improvements in the sharing of holding information and ILL arrangements, many East Asian materials are still difficult to obtain and interlibrary loan for East Asian materials is not yet handled by a defined set of processes.

Still, it is not impossible to implement quality improvement approaches in an East Asian collection. The collection may be unable to set standards for high-quality services because of process irregularities in some areas. However, it can still examine all the processes that are well established and that people are accustomed to doing. The quality improvement approach encourages the discovery of possibilities of doing things differently to improve the efficiency of work. Some improvements may be small, but they add up. The East Asian collection may discover that its old processes are not working effectively to handle customer demands and that it is not taking advantage of the new services available elsewhere. 
Surely, it looks awkward to have this sort of practice in the East Asian collection, which is akin to a small neighborhood restaurant serving loyal customers, but it does not mean that this practice will not work and should not be done. Nowadays, even a neighborhood restaurant is not free from competition coming from the larger, outside market forces. It requires the change in staff mind-set from quick-fix approaches to close, systematic examination of processes and problems. It is timeconsuming and challenging. So far, the East Asian collection has had little incentive to take on this process improvement approach unless it is forced to do so by upper library management.

\section{Team-based Environment and Staffing Changes}

Along with customer focus and continuous quality improvement, teamwork is an important component of TQM. To enable customer-focused service delivery and continuous improvement of service quality, people who work on the front line must be empowered and given skills to own the processes they perform. In TQM, they are given authority to make decisions regarding the work they do. ${ }^{17}$ They are trusted as being the most knowledgeable about customer needs and expert in the work they do. When team members are trained to operate in a team-based environment, teamwork helps to more quickly change processes to reflect customer needs and continuously improve the quality of services. Moreover, empowered workers' productivity increases greatly.

The advantages of teamwork are recognized almost everywhere, including the library setting, and recent job descriptions for librarian positions often mention something like the ability to work with a team of people. Saying it without changing things is easy, however. Moving to a team-based environment truly requires the shift of decision-making structure from a top-down structure concentrated in the top management to a decentralized one where decision-making can happen anywhere as appropriate. This change results in a flatter organizational structure. Restructuring an organization is always painful, and moving to a teambased organization is no exception. Not many academic libraries have gone through this painful change to the teambased organizational structure.

\section{University of Arizona Library Reorganization}

The University of Arizona is one of the few academic libraries that has restructured in this way. In 1993, it drastically restructured its former hierarchical organization to a team-based one. The major drivers for this reorganization are the same as the ones for TQM approaches: To survive in the competitive environment of customer-focused services with continuous quality improvement by the entire work force. In addition, more impending and practical issues such as substantial budget cuts and the need to implement an automated library system without additional new resources were the major factors that made the library pursue reorganization. ${ }^{18}$ Restructuring to a team-based organization by consolidating some departments and reducing administrative hierarchy was intended to produce an effective reallocation of reduced human resources. All the previous departments in the library were eliminated, and in their place, teams with distinctive functions focused on customer groups or a set of processes were formed. For example, Integrative Services Teams, consisting mostly of librarians, provide direct services to customers with responsibilities in collection development, reference services, instruction, and faculty liaison for assigned subject areas corresponding to academic programs on campus and for undergraduate education.

\section{University of Arizona East Asian Collec- tion in the Team Environment}

The Oriental Studies Collection at the University of Arizona Library was an independent unit within the library, including Chinese, Japanese, and Middle East collections, before the reorganization. It had a department head and its own staff dedicated to collection development, technical 
services, and reference services. It was a fairly self-sufficient entity just like many other East Asian collections in the nation. After the reorganization, librarians for East Asian studies were placed in the Fine Arts / Humanities Team among other subject librarians such as in English literature, art, and music. This was because the East Asian studies department on campus belongs to the College of Humanities. The librarian for Middle Eastern studies was placed in the Social Sciences Team because the Middle Eastern studies department was part of the College of Social and Behavioral Sciences. The name of the Oriental Studies Collection still exists, but it has lost its distinct administrative functions within the library.

Within the team, East Asian librarians participate in various activities related to team operation and customer service issues in their subject areas. Also, they can be called on to serve on various other socalled cross-functional teams for administrative and issue-specific activities requiring organization-wide coordination, such as strategic planning, information resources management, and other annual projects created by the library's strategic plan and other directives. Team-based approaches in the library encourage staff participation in various activities and reporting/dialogue sessions. Thus, the variety of work that East Asian librarians perform has increased beyond the tasks specific to running the East Asian collection. Though placed in the team primarily concerned with public services with other subject specialist librarians, the East Asian librarians are still responsible for managing the technical processes for East Asian materials that require language expertise and special knowledge. Most of the work for the East Asian collection remains, in addition to an array of new work for the team and the library.

\section{Being in the Team-based Environment: Benefits and Drawbacks}

The University of Arizona Library's case is one of the possible staffing arrangements of East Asian studies librarians and staff in a team-based environment. Depending on various factors such as philosophy of the organization, size of the collection, customer profiles, and budgetary situations, staffing can take many forms in the team-based environment. However, no matter how East Asian librarians and staff are arranged in the team-based environment, the specialized work they do will not go away. The special tasks of the East Asian collection, induced mainly by language limitations, still exist. Team members are supposed to work together; however, East Asian librarians and staff are unlikely to obtain support from others for the special tasks they do. Only they can handle most of the tasks pertaining to non-roman-language information in an East Asian collection. In addition, more work for the team and the library in general will come to them, demanding more of their time.

\section{Customers in East Asian studies do not solely use vernacular-language materials.}

Moving to a team-based environment does not always have to be as drastic as it was in the case of the University of Arizona Library. A team structure could be implemented and work well within a large East Asian collection, just as the Special Collections in the University of Arizona Library has its own team. However, in the case of a small East Asian collection, the team-based environment is likely to incorporate the collection's one or two librarians in teams with other librarians and/or staff. Thus, the same issues seen in the University of Arizona Library reorganization are likely to surface. Librarians working with relatively small East Asian collections usually have both public and technical service responsibilities, but at the University of Arizona Library, they are placed with other librarians in a team that is focused primarily on direct customer services. This creates tension between those who expect East Asian librarians to focus on direct customer services and the East Asian librar- 
ians who still need to take care of technical services that no one else can manage.

One good thing about being placed in a team with other librarians is that East Asian studies librarians can have better communication with the mainstream librarians and a clearer understanding of the broad context of issues in mainstream librarianship and the library organization. ${ }^{19}$ As East Asian studies becomes more interdisciplinary, working with other subject librarians, such as in the humanities and social sciences, presents many opportunities to deliver innovative services in close collaboration with other units and people in the library. Customers in East Asian studies do not solely use vernacular-language materials. They also need English-language information and a variety of services such as electronic document delivery and information literacy education that mainstream librarianship offers and excels at. Many mainstream library issues, such as intellectual freedom, obviously affect East Asian collections as well. ${ }^{20}$

Being more conscious about costefficiency than public-sector organizations, for-profit organizations offer competitive prices for library services.

A team-based environment brings about more opportunities for sharing knowledge between East Asian studies librarians and other librarians and for working together to provide holistic librarywide services for the customers in East Asian studies. It helps East Asian studies librarians to get out of their "silo" in the East Asian collection and lets them see a whole picture of interrelationships and processes in the library and its surrounding environment. ${ }^{21}$ Systems thinking helps East Asian studies librarians see how their collection is connected to the rest of the library.

Team-based environments bring both advantages and disadvantages to the East Asian collection. Depending on how the organization is structured and how work requirements are arranged for East Asian studies librarians, the move to a teambased environment can work out well for them. At the same time, however, there is a great danger of making things miserable for the East Asian studies librarians if their extra work responsibilities are not considered in the new environment.

\section{Specialization versus Generalization: \\ Finding a Middle Ground}

The University of Arizona Library's case demonstrates that it is difficult to decompose the specialized functions of the East Asian collection and put them in a librarywide team-based environment. The generalized work in the team-based environment and the specialized work in the East Asian collection are often in conflict. Having East Asian studies librarians on a team with other subject librarians requires a clear understanding and sufficient considerations of the special characteristics of their work. The library needs to accommodate these characteristics when establishing a staffing model based on a team-based environment. Otherwise, the East Asian collection could be further marginalized as the organization gears toward mainstream library issues. It would be worse than the traditional organizational structure where the East Asian studies librarians, although marginalized, could at least exercise some autonomy over their collection. They should be given sufficient time and support to do their original work for the customers in East Asian studies, which only they can handle. Taking up too much of their time to perform duties that others could handle is not an efficient use of their specialized skills and knowledge.

This fine point-how much time East Asian studies librarians should give up to perform duties not related to their collection-calls for negotiations between them and the library's other stakeholders. The conflict between the specialized nature of their work and general work requirements in the team-based environment will always exist, and each organization will have to find a middle ground. A library cannot simply enforce a general 
team-based structure on the staffing of East Asian studies librarians. Adjustments must be made in staffing arrangements and work requirements. If the library tries to become a flexible organization, this can be achieved. The University of Arizona Library's team-based structure has matured enough to offer greater flexibility for the librarians running the East Asian collection; however, whether putting the East Asian collection in the teambased environment will be successful in the long run remains to be seen.

\section{Budgetary Restraints: Pressure to Become More Cost-efficient}

Organizational changes in the academic library environment, especially in public universities, are often made in response to the pressure to reduce operating costs under the grim prospect of sustainable funding support. Changes engineered with management concepts such as TQM are implemented to enhance the organization's ability to find ways to reduce costs. Through such changes, all the existing processes in the library can be under close scrutiny to improve cost-efficiency.

As pressure toward increased cost-efficiency mounts across academic libraries, an East Asian collection is likely to face more challenges than other units of the library. Serving customers in East Asian studies with the East Asian collection is inherently more costly than serving a larger number of customers in mainstream academic programs. Many resources are spent on running the East Asian collection, yet it benefits only a small group of people on campus. With the same amount of resources, the library can serve and benefit far more people in mainstream academic programs. Thus, if the library looks at the cost-efficiency of the East Asian collection compared with other service areas of the library, the East Asian collection definitely has to go. It is not as cost-efficient as the librarywide average. However, as long as the East Asian studies program continues to exist on campus, the library has to serve it with the East Asian collection. Thus, the collection remains alive but continues to receive lukewarm funding support. Other than funding support from outside the library, the only way to provide services within resource constraints is to improve the cost-efficiency of the library's processes.

A smaller East Asian collection integrated with other main library collections and processes, often in a team-based environment, provides more opportunities to improve cost-efficiency. A small East Asian collection is unable to handle all of its technical and public service processes in-house and often shares them with main library departments. Being more integrated with main library processes, the East Asian collection naturally is driven to identify those processes that can be handed off to other departments and those that cannot be handled by mainstream processes because of language limitations. This helps develop solutions such as outsourcing and modifying or creating new processes, some of which are handed off to main library departments.

Outsourcing as a way to reduce or eliminate costs exists in many parts of library operations, including cataloging, collection development, physical processing, and document delivery. ${ }^{22}$ Being more conscious about cost-efficiency than public-sector organizations, for-profit organizations offer competitive prices for library services. Outsourcing of cataloging of East Asian language materials has been around for a while. Although not necessarily seen as outsourcing, several book vendors for East Asian materials offer approval plans that preselect titles based on a number of parameters set by the client library, alleviating the workload for collection development. The market for outsourced East Asian library services is still small and so corporations are not yet able to offer the competitive prices in this area, which would be realized by a larger market size. For now, outsourcing is not always a cost-efficient solution for East Asian collections, but this may change. Conducting a cost-benefit analysis of pos- 
sible outsourcing is worth the effort because it determines whether it is more cost-efficient than the existing in-house processing and proves to the library administration that the decision to outsource or not to outsource is based on the objective analysis of costs and benefits.

However, cost-benefit analysis does not necessarily address the quality of outsourcing services. Outsourcing may reduce costs but may not offer the quality of services that library customers need. Outsourcing of academic library services tends to be successful in delivering highquality services where processes are standardized and services are targeted to a large number of general library users in general subjects and academic levels, just as books coming from blanket orders are sufficient for undergraduate collections, but selection of more advanced and specialized titles are left to librarians. An East Asian collection serves a small group of customers with research and graduatelevel materials on nonmainstream subjects on campus. This makes existing general collection development outsourcing services less effective. Subject specialists closely connected to the academic department on campus can use the financial resources more effectively by selecting appropriate titles with detailed knowledge of the information needs of a small number of faculty and students with distinctive research and study focuses.

\section{Becoming More Competitive, Accountable, and Strategic}

Outsourcing offers opportunities to improve the cost-efficiency of serving customers in East Asian studies. At the same time, outsourcing offered by competitive enterprise questions the value of the professional work of cataloging, collection development, and many other areas that are traditionally done exclusively inhouse at the library. This competitive threat should drive East Asian studies librarians to look at their work processes and service quality to prove that having critical library services in-house is more effective in supporting East Asian stud- ies on campus, even though it may be more costly than outsourcing. This competitive threat is not solely an issue for East Asian studies librarians. The value of the whole library profession is in question under proliferating information services using emerging technologies. This challenge to the value system can result in some old work going away and some new work coming in. During this transition, the tasks that librarians can do best will stay, but this has to be proven with concrete evidence of effectiveness and excellence. The East Asian collection is no exception in having to prove to the library administration that its librarians can do the job best with proven effectiveness and efficiency exceeding, or on a par with, those of competitors.

\section{The East Asian collection might as well contribute to the planning process by presenting its own assessment of its current state and future vision.}

Assessing product quality and customer satisfaction is critical to qualitydriven management. Academic libraries were traditionally content with measuring inputs and outputs such as budget, collection, and staff size. However, quality-driven management demands tangible evidence that the library actually achieves its intended results; that it is providing high-quality services and products; and that it is doing so in a cost-efficient and effective way.

As mentioned earlier, an East Asian collection is often not as cost-efficient as mainstream library operations. This fact has to be communicated to the rest of the library. The same level of quality standards of customer services and internal processes for the mainstream library are not always applicable to the East Asian collection. But by examining and communicating every work process, especially its special aspects, the East Asian collection should help demonstrate that it is doing its best, even though it does not look as efficient as mainstream library operations. 
The East Asian collection can no longer take its work for granted. It needs to assess and demonstrate its effectiveness and efficiency to the library in order to be accountable for its financial and human resources and to obtain better understanding of its operations. Measures of success can be powerful tools for communicating to stakeholders about the organization's performance and for marketing the organization. ${ }^{23}$ Likewise, good performance management helps demonstrate the viability of the East Asian collection, so a culture of assessment should be there. It is an environment where services are assessed and planned based on facts, research, and analysis in order to maximize the outcomes for customers. ${ }^{24}$

Strategic planning is a concept that sets organizational goals based on environmental scanning. ${ }^{25}$ It aligns all organizational units and directs resources to achieving focused goals that make the organization successful in a changing environment. Strategic planning in nonprofit organizations tends to be a long list of everything the organization does, often just a wish list of things it wants to do for all stakeholders. ${ }^{26}$ Indeed, strategic planning in the library setting was very much like this. However, it now is becoming a real binding force in library administration in that it directs resources to selected strategic areas based on strategic goals and objectives and it demands that library units report their performance on achieving strategic objectives. Librarywide strategic planning will require the East Asian collection to be in alignment with other library units toward achieving strategic goals and objectives in terms of what kinds of work to concentrate on.

With librarywide strategic planning in place, the library units do not have the luxury of continuing to do things that are not deemed strategic in the same old manner. If not involved in the planning process, the East Asian collection may end up having to devote its own resources for strategic objectives that it does not necessarily share. Otherwise, it may be finan- cially penalized for not making contributions or being a part of the plan. Active participation in the planning process is necessary to get the collection's position reflected in strategic direction and implementation plans. The East Asian collection might as well contribute to the planning process by presenting its own assessment of its current state and future vision. What are its strengths and weaknesses? What are the major opportunities and threats out there that may affect its future? Which elements are unique to the East Asian collection, and which ones are shared with mainstream librarianship? What possible plans of action move it toward its vision? A good strategic plan that the East Asian collection can support and be part of should emerge through discussion of these issues. Here again, communication is the key.

Strategic planning directs the organization to focus its efforts on the key areas it wants to continue to excel at or improve. In private industry, after a strategic plan is made with a defined focus of activities, an organization, in an extreme case, can withdraw entirely from nonstrategic activities. For example, the recent economic slowdown has made quite a few corporations withdraw from markets in which they find themselves unable to compete successfully. Unlike public and nonprofit organizations, they do not have an obligation to serve customers when they cannot make enough profits. They can simply go away, allowing other, more competitive corporations to take over the market. In the academic library setting, the library cannot simply stop providing a certain service, even though it is deemed not strategic or not cost-efficient. The library still has a responsibility to meet the needs of customers across the campus. Strategic planning in the academic library setting cannot be as clear-cut as it is in the business industry.

An East Asian collection may well face this dilemma of needing to provide services while knowing it is not strategic or cost-efficient. It cannot blindly pursue ultimate customer satisfaction because it 
has to operate within the resources allocated. It will be faced with hard choices about what to give up to stay focused on priority tasks. It is about doing the best with the resources it receives from the library. The East Asian collection needs to demonstrate that its customers need its services and that it is doing the best it can to provide them as efficiently as possible. Support from the library is the key to sustaining good customer services. Through demonstrated service effectiveness and efficiency, communication of special issues to the library, and active participation in the planning process, this dilemma for the East Asian collection can be alleviated.

\section{Conclusion}

The special characteristics of the East Asian collection that legitimized its detachment from mainstream library operations still hold true. However, continued budgetary restraints may bring into question the cost-efficiency of running the East Asian collection separately from main library operations. There may be times when the academic library has to make a hard choice. Merging the collection with the rest of the library so as to remove an extra administrative layer and overhead costs is one possible choice for streamlining library operations and costs.

Organizational changes are difficult for everyone in the library, not just for the people working in the East Asian collection. Moreover, organizational changes in the academic library do not always work against the East Asian collection. An organizational move to customer focus reinforces East Asian studies librarians' excellence in working closely with customers. Quality-oriented management prin- ciples in TQM can help East Asian collections become proactive in designing innovative customer services with continuous improvement of services and increased efficiency and effectiveness. In addition, organizational changes can offer a good opportunity to get away from the traditional ways of running the collection and to take a fresh look at library services from a larger point of view. The issue is not so much about running an East Asian collection. Rather, it is about how the collection can serve the needs of its customers in East Asian studies, mobilizing all the resources the library has. There should be no conflict between the East Asian collection and the library mainstream.

Forces driving organizational changes in the academic library setting can help the East Asian collection better communicate the unique characteristics of serving its customers to the rest of the library. Better strategies and ideas for serving customer needs can come through closer interaction with other people in the teambased environment. Efforts toward improving customer satisfaction, work processes, cost-efficiency, and financial accountability will make the East Asian collection more visible to the rest of the library and enable it to share its special issues more broadly with others. Otherwise, centrally initiated organizational changes across the library will easily swallow the East Asian collection, sacrificing the services for customers in East Asian studies in the process. Some compromise may be necessary through organizational change; however, coping with change in good faith will move us ahead, better able to take advantage of the opportunities brought about by change.

\section{Notes}

1. Diane E. Perushek, "A Branch Apart: East Asian Collections in a Research Library Context," Committee on East Asian Libraries Bulletin, no. 101 (Dec. 1993): 10.

2. Susan Lee, "Organizational Change in Research Libraries," Journal of Library Administration 18, no. 3-4 (1993): 129-30.

3. Ai-Hwa Wu, "Reality Check: The Changing Role of the East Asian Studies Librarian in North America," Journal of East Asian Libraries, no. 119 (Oct. 1999): 4-6. 
4. Cecily Johns, ed., Selection of Library Materials for Area Studies: Part I. Asia, Iberia, the Caribbean, and Latin America, Eastern Europe and the Soviet Union, and the South Pacific (Chicago: ALA, 1990), x-xi.

5. Clare B. Dunkle, "Why Put East Asian Materials in a Separate Collection? The Issue of Access," Journal of Academic Librarianship 19, no. 4 (1993): 216-18.

6. Perushek, 9-11.

7. Ibid. $50-51$.

8. Guy St Clair, Total Quality Management in Information Services (London: Bowker-Saur, 1997),

9. Ibid., 85.

10. Joseph R. Diaz and Chestalene Pintozzi, "Helping Teams Work: Lessons Learned from the University of Arizona Library Reorganization," Library Administration and Management 13, no. 1 (winter 1999): 27.

11. Wu, "Reality Check," 1.

12. St Clair, Total Quality Management in Information Services, xxi.

13. Ibid., 53-55.

14. Susan Jurow and Susan B. Barnard, ed., Integrating Total Quality Management in a Library Setting (New York: Haworth Pr., 1993), 5-6.

15. Ibid.

16. Catherine A. Larson, "Customer First: Using Process Improvement to Improve Service Quality and Efficiency," Reference Services Review 26, no. 1 (spring 1998): 52.

17. St Clair, Total Quality Management in Information Services, 145.

18. Christine E. Kollen, Nancy R. Simons, and Jennalyn W. Tellman, "Libraries in Split Positions with Both Technical and Public Services Responsibilities: The University of Arizona Library Experience," Advances in Library Administration and Organization 15 (1997): 210-11.

19. Wu, "Reality Check," 5.

20. Ibid.

21. Shelley Phipps and Cathy Larson, "The Five Disciplines: Learning Organizations and Technological Change," in Information Imagineering: Meeting at the Interface, ed. Milton T. Wolf, Pat Ensor, and Mary Augusta Thomas (Chicago: ALA, 1998), 202.

22. Karen R. Wilson and Marylou Colver, ed., Outsourcing Library Technical Services Operations: Practices in Academic, Public, and Special Libraries (Chicago: ALA, 1997), xvii.

23. John C. Sawhill and David Williamson, "Mission Impossible? Measuring Success in Nonprofit Organizations," Nonprofit Management and Leadership 11, no. 3 (spring 2001): 384-85.

24. Amos Lakos, "The Missing Ingredient-Culture of Assessment in Libraries: Opinion Piece," Performance Measurement and Metrics 1, no. 1 (Aug. 1999): 5.

25. Douglas G. Birdsall, "Strategic Planning in Academic Libraries: A Political Perspective," in Restructuring Academic Libraries: Organizational Development in the Wake of Technological Change, ed. Charles A. Schwartz (Chicago: ACRL, 1997), 253.

26. Robert S. Kaplan, "Strategic Performance Measurement and Management in Nonprofit Organizations," Nonprofit Management and Leadership 11, no. 3 (spring 2001): 358. 